\title{
PATIENTS' EXPERIENCES OF SELF-ADMINISTERED ELECTROTHERAPY FOR SPASTICITY IN STROKE AND CEREBRAL PALSY: A QUALITATIVE STUDY
}

\begin{abstract}
Lise-Lotte JONASSON, RN, PhD ${ }^{1}$, Ann SÖRBO, MD, PhD², Per ERTZGAARD, MD, PhD ${ }^{3}$ and Leif SANDSJÖ, PhD 4,5
From the ${ }^{1}$ Department of Nursing, School of Health and Welfare, Jönköping University, Sweden, ${ }^{2}$ Region Västra Götaland, Södra Älvsborg Hospital, Department of Neurology and Rehabilitation and Department of Research, Education and Innovation, Borås, ${ }^{3}$ Department of Rehabilitation Medicine and Department of Medicine and Health Sciences, Linköping University, Linköping, ${ }^{4}$ Department of Work Life and Social Welfare, Faculty of Caring Science, Work Life and Social Welfare, University of Borås, Borås and ${ }^{5}$ Division of Design \& Human Factors, Department of Industrial and Material Science, Chalmers University of Technology, Gothenburg, Sweden
\end{abstract}

\begin{abstract}
Objective: To explore patients' experiences of a selfadministered electrotherapy treatment for muscle spasticity in cerebral palsy and stroke; the Exopulse Mollii Suit ${ }^{\circ}$.

Design: Qualitative design with an inductive approach
\end{abstract}

Subjects: Fifteen patients with spasticity due to stroke or cerebral palsy, participating in a previous randomized controlled trial evaluating the treatment concept.

Methods: Information letters were sent to all potential participants $(n=27)$ in the previous study. Semistructured interviews (21-57 $\mathrm{min}$ ) were carried out with all subjects who volunteered $(n=15)$, administered by an experienced interviewer who was not involved in the previous study. Transcribed interviews were subject to content analysis.

Results: The $\mathbf{5}$ categories that emerged from the content analysis were "New method gives hope", experiences related to "Using the assistive technology", "Outcome from training with the assistive technology", "The assistive technology" and "Taking part in the study". Respondents felt hopeful when included in the previous study, motivated when experiencing a treatment effect, and disappointed when not.

Conclusion: The qualitative approach used in this study elicited complementary information that was not evident from the previous randomized controlled trial. This included statements regarding increased mobility, reduced spasticity, reduced use of medication, and problems related to using the treatment concept.

Key words: patients' experiences; self-administered; electrotherapy; spasticity; Mollii Suit ${ }^{\circledR}$; qualitative study.

Accepted Dec 6, 2021; Epub ahead of print Dec 22, 2021

J Rehabil Med 2022; 54: jrm00263

Correspondence address: Lise-Lotte Jonasson, Department of Nursing, School of Health and Welfare, Jönköping University, Sweden. Email: lise-lotte.Jonasson@ju.se

$\mathrm{M}$ uscle spasticity is common after injury to the central nervous system, affecting the patient's motor function and ability to carry out everyday activities. Spasticity appears in more than $20 \%$ of stroke patients and in more than $80 \%$ of subjects with cerebral palsy $(\mathrm{CP})(1,2)$.

\section{LAY ABSTRACT}

Fifteen patients who had tried the assistive technology Exopulse Mollii Suit $®$, an electrotherapy concept against muscle spasticity housed in a tight-fitting suit, were interviewed about their experiences. Increased mobility, reduced spasticity, and a reduction in the use of medication for spasticity-related symptoms were positive outcomes described by participants, although this was not experienced by everyone. Interest in continuing using the treatment for home-based training after the study was based on each individual's experience of whether the treatment was effective, the (initial) motivation, and determination to try the new concept, the support from relatives or home service personnel to use the treatment and overcome difficulties that might appear, and the overall usability of the electrotherapy suit. The participants' interest in using the training concept thus depended on the outcome from using the suit, motivation to use the suit, the usability of the suit, and available support when using the suit.

Treatment for spasticity includes physiotherapy and training, as well as pharmacological treatment, if needed. One mode of physiotherapy is electrical stimulation, commonly referred to as therapeutic electrical stimulation (TES) or transcutaneous electrical nerve stimulation (TENS). TENS can be difficult to use in clinical practice because of practical difficulties attaching the electrodes appropriately and using the TENS during training. Therapies that can be performed by the patient, without the assistance or presence of a therapist, are lacking. A TENS application integrating stimulation electrodes in a full-body garment, the "Mollii" (Mollii ${ }^{\circledR}$, Inerventions AB, Stockholm) (Fig. 1 ), addresses this by making the therapeutic electrical stimulation of spastic muscles available as a selfadministered treatment for use in the home environment. The rationale of this assistive technology (AT) is to reduce spastic reflexes and muscle stiffness by stimulating the antagonists of the muscles affected by spasticity (reciprocal inhibition). Thus, training can be performed during or immediately after electrotherapy with less spastic musculature, thereby allowing increased range of motion and less movement resistance than in spastic conditions. 


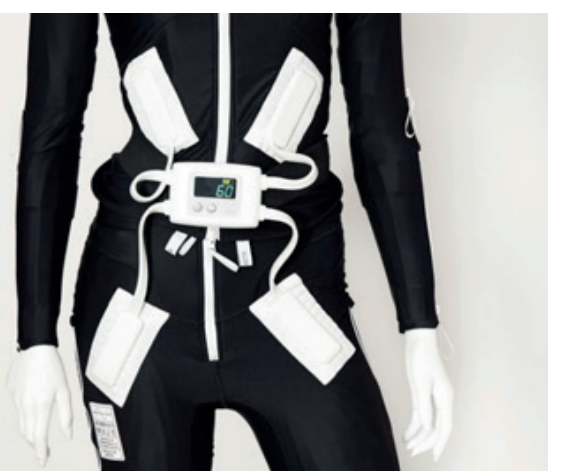

Fig. 1. The assistive technology comprising a tight-fitting, full-body garment and a control box worn at the waist. The garment has 58 stimulating electrodes integrated in relation to 40 different muscles, which enables TES therapy to be self-administered according to the individual profile programmed by a professional in a try-out session and stored in the control box (Mollii ${ }^{\circledR}$, Inerventions $A B$, Stockholm).

This specific AT treatment concept has been evaluated in 3 non-controlled studies (3-5) and in 1 double-blind, randomized, controlled, cross-over trial (RCT) (6). In the latter, 27 participants with muscle spasticity due to CP $(n=12)$ or stroke $(n=15)$ used the AT with and without electrical stimulation for 6 weeks each, followed by a "wash-out" period of 6 weeks not using the AT. Fifteen of the 27 participants fulfilled the treatment protocol in terms of recommended use, i.e. $1 \mathrm{~h}$ use every other day (3-4 times a week). The study did not find any statistically significant differences in any of the chosen outcome variables between the active and non-active treatment periods. However, mobility-related outcomes generally improved after both treatment periods. After the RCT study, with its recommended use of the AT in combination with training every other day, the participants continued to use the AT under free conditions, i.e. each participant could decide how much and when to use the AT during this free period of 34 weeks. At the end of the 1-year study $(18+34$ weeks $)$, all the participants were offered the opportunity to keep the AT they had been using. This offer was designed to handle the ethical issue of "intervention withdrawal" and this "participa- tion bonus" was not presented to the participants as part of the study until the final follow-up.

Even though no significant differences between the active and non-active periods of the RCT study could be demonstrated, treatment effects were experienced by some of the study participants and reported to the professionals conducting the study. These reports on reduced spasticity levels and improved function were given by participants as additional information in diaries and open questions in the study questionnaires as part of the RCT, as well as from informal observations and communication with the rehabilitation team.

The focus of this study was to interview participants, in order to learn about their experiences beyond what was covered by the instruments and questionnaires used in the RCT study (6).

\section{Aim}

The aim of this study was to explore patients' experiences from a previous study evaluating self-administered electrotherapy and training for muscle spasticity in $\mathrm{CP}$ and stroke.

\section{METHODS}

This qualitative study focused on user experiences from the previous study evaluating a new treatment concept for muscle spasticity. This study was set up as a semi-structured interview study with an inductive approach, thereby giving the respondents the opportunity to comment on both the treatment concept and the more formal procedures of taking part in a study.

\section{Previous study}

The target group for the previous study comprised patients with spasticity due to stroke or CP. The inclusion criteria were having spasticity interfering with daily life (at least $1+$ on the modified Ashworth scale), having preserved walking ability (with or without walking aids), having reached the age of 18 years and being able to understand the treatment and evaluation protocol. For detailed information on the previous study design, see Fig. 2 and Ertzgaard et al. (6).
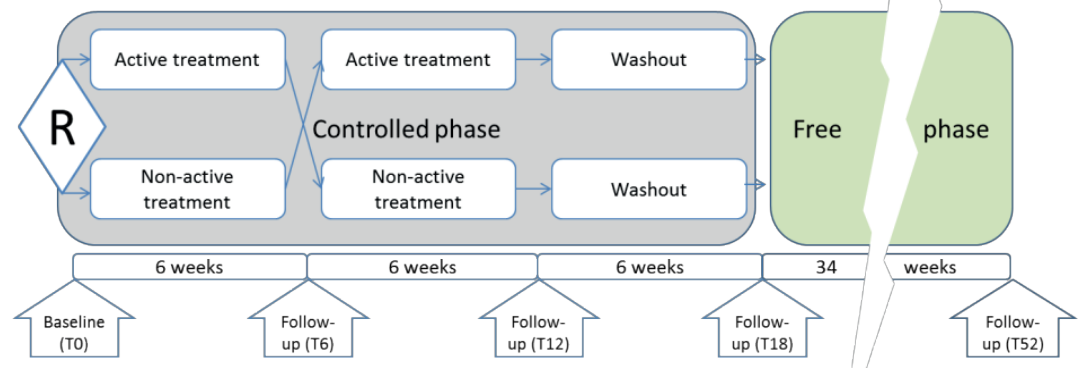

Fig. 2. The previous study set out to evaluate the treatment concept. During the controlled phase, the participants were instructed to use the treatment three to four times a week (every other day), followed by a six-week wash-out period. The second part of the study - the free phase - then followed, enabling the participants to use the treatment at will. 
Table I. Respondents' demographics and physical status

\begin{tabular}{|c|c|c|c|c|}
\hline Feature & $\begin{array}{l}\text { Respondents } \\
(n=15)\end{array}$ & $\begin{array}{l}\text { Spasticity } \\
\text { Mean [range] }\end{array}$ & $\begin{array}{l}\text { Age } \\
\text { Mean [range }\end{array}$ & \\
\hline Sex (all) & 15 & $3.3[2-5]$ & 53 [26-70] & \\
\hline Male & 5 & $3.6[2-5]$ & 51 [30-67] & \\
\hline Female & 10 & $3.1[2-4]$ & $54[26-70]$ & \\
\hline Diagnosis (all) & 15 & $3.3[2-5]$ & $53[26-70]$ & \\
\hline Stroke & 8 & $3.2[2-5]$ & 58 [43-67] & \\
\hline Cerebral palsy & 7 & $3.3[2-4]$ & $47[26-70]$ & \\
\hline Disability & $\begin{array}{l}\text { Normal/next } \\
\text { to normal }\end{array}$ & $\begin{array}{l}\text { Light to } \\
\text { moderate }\end{array}$ & Pronounced & $\begin{array}{l}\text { No voluntary } \\
\text { control }\end{array}$ \\
\hline Right arm 15 & 8 & 4 & 3 & 0 \\
\hline Left arm 15 & 8 & 3 & 4 & 0 \\
\hline Right leg 15 & 5 & 8 & 2 & 0 \\
\hline Left leg $\quad 15$ & 5 & 6 & 4 & 0 \\
\hline
\end{tabular}

Spasticity was measured in the previous study using the Modified Ashworth Scale (0-5), while disability was assessed in 4 steps, depending on the degree of motor control. This ranged from normal/next to normal (not interfering with activity execution), light to moderate reduced function (interfering, but not hindering activity, i.e. making activity slower or with reduced dexterity), pronounced reduced control (performed mainly in synergistic patterns) and lastly no voluntary control.

Participants in the previous study and respondents in this study

All 27 participants in the previous study were sent an information letter in which they were asked about their interest in taking part in a follow-up study. Fifteen accepted by signing and returning the informed consent form and they became the respondents in this study. From here on, the word "participants" is used to denote the 27 participants in the previous study, while "respondents" is used exclusively for the 15 individuals interviewed in this qualitative study. An overview of the respondents' diagnoses, disability, age, sex and level of spasticity is given in Table I.

The previous study was approved by the regional ethical vetting board of Linköping (2013/150-31) and the present followup interview study was approved by the same board based on a supplementary application to 2013/150-31.

\section{Data collection}

Semi-structured interviews were conducted face to face by the first author (LJ) 6-12 months after the end of the previous study. All the respondents chose to have the interview at the rehabilitation clinic where the previous study had been conducted. The interviews were recorded on a digital recorder and completed in $21-57 \mathrm{~min}$.

The interviews focused on the respondents' experiences (7) of taking part in the previous study, starting with the question "Looking back at your participation in the study, what comes to mind?", followed by further questions to support the elicitation of important information regarding the use and outcome of using the AT. Each respondent was given complete freedom and time to describe all of his/her thoughts and experiences related to participation in the former study and using the AT and how it affected his/her life (8).

\section{Data analysis}

Inductive qualitative content analyses were carried out according to Graneheim \& Lundman (9). The audio recordings were transcribed verbatim by LJ. All the authors had access to and familiarized themselves with the interview material. The transcribed interviews were read repeatedly by LJ and LS before identifying meaning units and shortening them to produce their condensed meaning units in line with the aim and specific focus of this study (see Table II). The condensation of meaningful units was first performed individually (LJ and LS) and then in collaboration to find codes. The codes were grouped into subcategories and then into categories (Table II).

\section{RESULTS}

Qualitative content analysis of respondents' experiences of participating in the previous study and using the new treatment method resulted in 5 categories based on 14 sub-categories presented in Fig. 3 and further described under separate headings below.

\section{New method gives hope}

This category covers the respondents' everyday experiences related to disability/muscle spasticity and the expectations related to learning about the new method and being invited to take part in the previous study.

\section{Hope of improvement}

All the respondents share the experience of muscle spasticity and how it affects everyday life. Learning about a new treatment that has the potential not only to mitigate muscle spasticity, but also to be performed by the person him/herself in the home environment, was encouraging. The respondents hoped that the new therapy would be effective and could be an alternative to other treatments, such as botulinum toxin injections (referred to as "Botox" by the respondents) and oral baclofen. Interest in testing the treatment concept came, at least in part, from the hope that the treatment might reduce spasticity without the side-effects experienced from pharmacological treatments. One respondent who had had a negative experience of using the AT still hoped that the new therapy could be an alternative to "the injections".

"If [the AT] is not improved, I'd like to start using Botox again, as it makes me feel better, but it's a pity because it feels good to get rid of the injections." $(\mathrm{H})$

Table II. Exemplifying the different steps of the content analysis

\begin{tabular}{llll}
\hline Meaning unit & Condensed meaning unit & Codes & Sub-category \\
\hline $\begin{array}{l}\text { The garment was tight, could not do it myself to } \\
\text { my disability }\end{array}$ & $\begin{array}{l}\text { Difficult to don the garment } \\
\text { without assistance }\end{array}$ & $\begin{array}{l}\text { Difficult to don the } \\
\text { garment }\end{array}$ & Design of the AT \\
$\begin{array}{l}\text { I used the garment while training, the muscles } \\
\text { felt less rigid afterwards and I thought that my } \\
\text { walking improved }\end{array}$ & $\begin{array}{l}\text { Easier to move about and walk } \\
\text { after using the garment }\end{array}$ & $\begin{array}{l}\text { Improved mobility } \\
\text { The astive technology }\end{array}$ & $\begin{array}{l}\text { Spasticity and } \\
\text { mobility }\end{array}$ \\
\hline
\end{tabular}




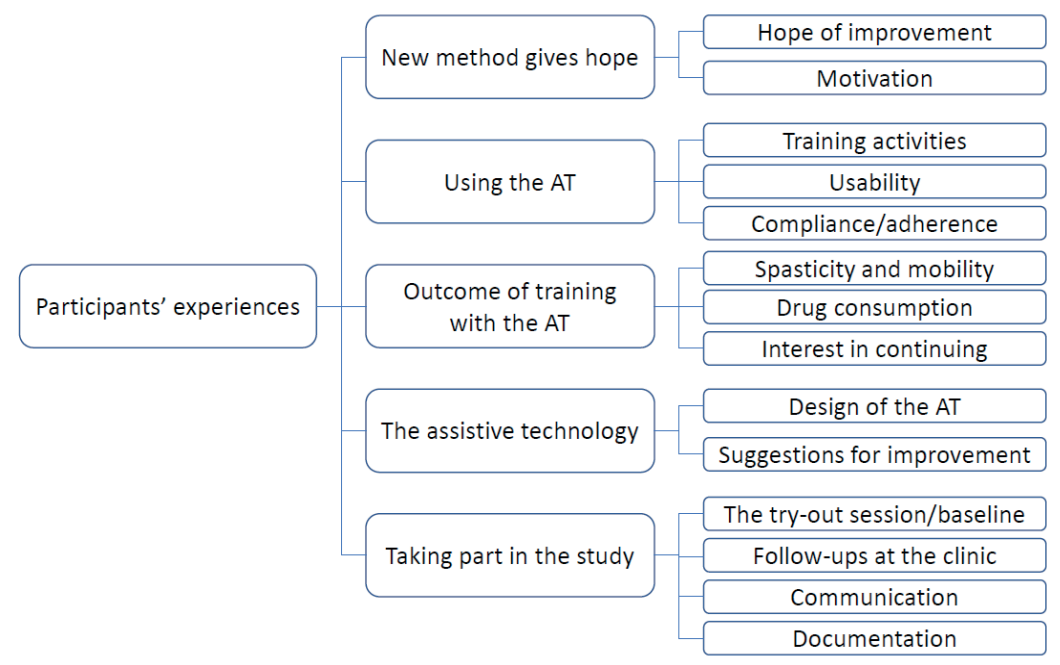

Fig. 3. Overview of the five categories and 14 sub-categories emerging from the interviews. the AT to be used during regular physiotherapy sessions.

\section{Usability}

The respondents described difficulties putting on the garment, as it was designed for a tight fit, which made the zips on the garment difficult to close (especially considering many respondents' limited hand function). Some found their own creative solutions for putting on the garment. Some needed help from relatives or home service personnel.

"Planning is needed... dependent on others helping out, dependent on help. " (D)

Another concern that was raised was that it was difficult to change the

\section{Motivation}

The respondents relate the feeling of being noticed, being someone special, and/or being selected when asked about their interest in taking part in the study. These feelings increased their motivation and interest in volunteering for the study. The chance of becoming more autonomous and active as a result of the treatment was reported to be stimulating, as well as a powerful incentive to participate in the study. Moreover, the urge to "do the right thing", i.e. contribute to research and development, was mentioned as a reason to enrol in the study.

One motivating factor was also the potential to reduce the use of medication. Drugs such as botulinum toxin were described with negative connotations and concerns about being harmful to the body.

"Ideally, I want [the AT], because the poison you inject into your body is not good in the long run." (O)

\section{Using the assistive technology}

This category covers the respondents' experiences of following the training programme, including the TES treatment, the practical circumstances related to putting the garment on and taking it off, and general use of the AT.

\section{Training activities}

The respondents said that they did not see the prescribed exercises with the garment as regular training, but as a pleasant activity in which they were relaxed, thereby increasing compliance.

"I don't see it as training. It's a pleasant activity when I'm relaxed." (D)

In addition to the recommended training, some respondents added their own activities, such as an exercise bike, (short) walks, ball exercises, or taking

\section{control box batteries.}

\section{Compliance/adherence}

The dependence on others to assist with putting on the garment affected the self-administered aspect of the AT and made planning necessary in order to adhere to the prescribed treatment.

In addition to the suggested/recommended individual training activities, the respondents also described different ways of adhering to the prescribed use.

"Using [the AT] in combination with everyday chores" (D)

"The garment simplifies training at home. Continued use every other day... Practice has become a routine.... But... I've made it, I feel proud." (E)

"I think it's still fun to train so I always do 1 hour of [the AT]. That's longer than recommended because I think it's so nice. " (K)

\section{Outcomes of training with the assistive technology}

This category covers the respondents' accounts in terms of physical experiences of training with the AT and changes in the use of medication.

\section{Spasticity and mobility}

Some respondents described "things happening" in their bodies and that their bodies became softer and less tense. This made it easier to move different parts of the body, described as improvements related to "the arm" or "the leg". Reported effects also included finding it easier to walk, a change in walking pattern and the shoulder feeling "like I can lift more than before" (L). Muscle rigidity and tension experienced in the morning were described as being reduced after training using the AT, as well as general improvements in relation to how it used to be. 
"During the study, I managed using a single crutch, but now, when I'm not using [the AT], I need to use two crutches." (L)

Accounts were given of positive experiences while wearing the garment, being free from pain, reduced muscle tension, less nausea/sickness, and increased mobility.

"(I've) really been helped by the treatment. Less cramp and reduced muscle tone." (E)

The respondents' accounts of the effect and the duration of the effect differed, ranging from no effect at all to long-term effects. Effects were described as lasting half an hour, or up to several hours. Some respondents who did not experience any effect were anxious that their statement should be used as a general interpretation.

"[the AT] did not work for me, but it may be good for other users."

The respondents described spasticity-related pain in different body regions, including headache and migraine. Using the AT was said to affect the spasticity and thereby the pain. There were reports of becoming pain free, having less spasticity and improved sleep.

"The spasticity and pain are reduced..." (I)

\section{Drug consumption}

Some described training with the AT as an alternative to other therapy. Some of the respondents were able to reduce or completely stop using certain drugs. Some respondents said that they stopped taking drugs, such as diazepam, or medication for headache, as well as experiencing a reduced need for sleep medicine.

"(I) have stopped diazepam... [the AT] replaces medicine. Can manage without sleeping drugs." (E)

\section{Interest in continuing using the AT/treatment concept}

At the end of the previous study, the company offered all the participants in that study to keep the AT as their own and continue using it. Accounts to continue or to stop using the AT were given in this study.

"I now plan to train more... I think it's a good gadget for the person using it.” (L)

"(I) was not interested in getting a new [AT] at the end of the study. I don't believe in it. Disappointed.” (H)

\section{The assistive technology}

This category covers respondents' views of the design of the Mollii, what the design meant in terms of using the garment, and suggestions for improving the AT.

\section{Design of the Mollii Suit ${ }^{\circledR}$}

In order for all the electrodes integrated in the Mollii garment to make full contact with the skin, the garment was designed to have a tight fit. This tight fit was described by many as a problem, and numerous suggestions on how to make it easier to don and doff were given. The location of the zips made it difficult to open/close them. Zips could also get stuck. The location of the control box at the front of the garment (at waist level) interfered with some training activities. Furthermore, the garment material did not "breathe", which made the Mollii warm to wear.

Another concern was that the stimulation electrodes could be dislodged during training, e.g. in a supine position.

$$
\text { “...if I lie down ... I get the vibrations somewhere else.” (K) }
$$

\section{Suggestions for improvement}

Several suggestions of ways to improve the AT were given. Many related to the (necessary) tight design of the garment, which made it (too) difficult to put on and the zips difficult to use. An appropriate size/good fit of the garment and placement of the zips to enable easy reach was suggested.

The opportunity for the user to adjust the stimulation intensity was also put forward as a desirable option.

"...then I believe that, if it were turned up slightly, I am sure it would feel better.” (D)

There were suggestions on how to make the change of batteries easier and allow the use of rechargeable batteries. The respondents also expressed an interest in being involved in further developments to make the AT more usable.

\section{Taking part in the previous study}

This category included experiences from using the AT as part of a formal study, including the programming of individual stimulation levels at baseline, regular follow-ups with assessments, the study documentation, and contact/communication with the company.

\section{The try-out session/baseline}

The most important part of the try-out session was being fitted with a garment of an appropriate size. The respondents had different views of the specific AT they were given, such as it was too big, too small, and/or too tight. This indicates that the size of the garment was not always optimal, even though the company had been provided with information on body size prior to the try-out session. The respondents stressed the importance of an appropriate try-out session to provide the best conditions for communicating all the relevant information from the company representative, study team and respondents' perspective.

There were positive experiences from taking part in the formulation of rehabilitation goals based on goal attainment scaling (GAS). 


\section{Follow-ups at the clinic}

The respondents felt that they had been well taken care of and had received the appropriate information during the 5 follow-ups in the previous study (Fig. 2). Some said that the follow-ups should (perhaps) have included technical information and a less stressful schedule. Some of the tests were described as difficult to perform; even with the non-affected side (e.g. a fully functioning hand).

\section{Communication}

The respondents said that the communication with the company/AT provider is crucial. In the event of a problem, easy access to appropriate and timely support is a necessity. In the event of problems with the AT, oral and/or written support should be provided and delivery notice should be given.

"I called the guy and said that I wanted the garment, but there was no garment." (M)

\section{Documentation}

The respondents were asked to keep a diary during the previous study about their spasticity, pain, training activities, (general) health and things of note. The respondents in this study described this documentation as sometimes being difficult.

".... And then they had a survey, questions. ...you had to think a little bit.... to be able to answer those questions." (B)

\section{DISCUSSION}

The focus of this study was to interview patients taking part in a previous study to learn about their experiences beyond what was covered by the instruments, tests and questionnaires used in the previous study. The information given by the respondents in this study provided complementary information that can be valuable for providers and users of the Mollii Suit ${ }^{\circledR}$, but also important for any AT provider to observe when planning AT studies in rehabilitation medicine.

The rationale for this qualitative study was also to probe respondents' experiences of taking part in evaluating a new treatment concept and how these experiences may affect adoption, i.e. interest in continuing using this mode of treatment. Such interest can be seen as summarizing the overall experience of using the AT in terms of treatment outcome and usability, but also personal factors, such as motivation, life situation and support from the family, rehabilitation team and/or the provider of the training concept. In Fig. 4, the categorized experiences emanating from this study are presented in relation to these 4 dimensions that are recognized by clinicians as essential for successful technology-based interventions.

\section{Continued use related to outcome}

At the end of the previous study, when all the participants were offered the chance to keep the AT as their own, some respondents decided not to. This decision could be interpreted as the respondents not experiencing the anticipated effect on muscle spasticity, or perceiving unsatisfactory function and/or limited usability of the AT. This study indicates that those who continued using the AT did so because they thought that the training concept was satisfactory and/or effective. The positive experiences mentioned in this interview study included improved mobility, reduced spasticity and/or lower drug consumption.

The greater the treatment effect the respondents experienced, the more they were motivated to exercise. The training also affected respondents' pain experiences, with less pain and a reduced need for pain medication. Several respondents experienced improved quality of life, which has been shown to correlate with reduced disability in upper-limb post-stroke disability (10).

The treatment effect of the AT in combination with training ranged from no effect to a good spasticityrelieving effect. It is not possible to draw any conclusions about the extent to which the duration/amount of training or electrotherapy affected the outcome. Other studies have shown that both the intensity and frequency of training are essential for a positive outcome (11). This is in accordance with studies showing that physical activity has an effect, such as well-being both physically and mentally $(12,13)$.

A further outcome is the reduced need for drug treatment. Painkillers, sleep medication, and medication to reduce spasticity were mentioned. All these have potential side-effects and can cause fatigue, reduced muscle power and impaired concentration (14). The reduced need for drug treatment can be seen as a powerful indicator of the effect of the treatment and this has probably increased the level of interest in the treatment concept.

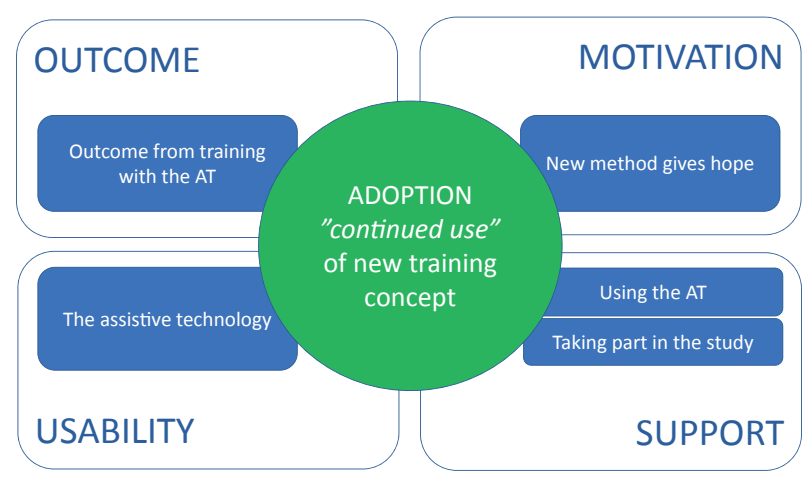

Fig. 4. The 5 categories emanating from this study presented in relation to dimensions considered in clinical practice. 
The respondents who did not experience any treatment effect said that they did not want to dismiss the AT, because it might have an impact on or be beneficial to other people. They were anxious that their statements should be used as a general interpretation that could exclude others from being offered the therapy.

"[the AT] did not work for me, but it might be good for other users."

This is an altruistic statement, showing a concern for others with disability and an understanding that a single treatment strategy does not suit everyone.

\section{Continued use related to Usability}

Problems with the AT, such as zips that broke and too short battery lifetime, were mentioned, and may have reduced interest in the treatment concept. The latter related to frustration due to the need to change batteries frequently, but also to environmental concern, as the AT was dependent on using non-rechargeable batteries.

A further usability concern was the possible dislodgement of electrodes during movement, as the garment was not perfectly aligned with the skin in the supine position, and that this could lessen the stimulation effect or even result in muscles other than those intended being stimulated.

The opportunity to allow the user to adjust the stimulation intensity during use was also put forward as a desirable option/improvement. These intensity adjustments can normally be performed by the company therapist, but the fact that the controlled part of the previous study was blinded made it more difficult for the company to intervene without revealing whether there was any stimulation. This might have been difficult for the respondents to understand.

\section{Continued use related to Support}

Respondents reported that they needed help from relatives or home service personnel to use the AT, as it was difficult to put on. This contrasts with the aim of the treatment to be a modality to be performed by the patients themselves in their home environment. As a result, adaptations of the AT to enable patients to don and doff the garment themselves appear to be important to increase both adoption and satisfaction.

The participants could have been given clearer, more specific information about who to contact when problems occurred. This might have had a positive impact on their continued interest/motivation. Designing an adequate support function is essential for clinical implementation, as previously reported by Paasche Orlow et al. (15).

\section{Continued use related to Motivation}

Trying a new treatment, based on a relatively advanced AT in terms of both construction and use, required both motivation and determination. This motivation and determination were shown and communicated by respondents in this study. The hope of improving gave the necessary motivation, and this is a significant factor in being able to make the change they wanted in their everyday lives. This is described by Bess et al. (16), who report that the more a person trains, the more trust he/she develops in his/her ability. In this study, the respondents who were motivated and saw solutions that could work were given the inspiration to continue training.

There was a strong desire among the respondents to find solutions to improve what was seen as problematic during the study. It was common for respondents to have ideas on how to improve/further develop the AT to make it easier to use, permeated by the idea of being independent. This idea of being part of a development process, and having experiences worth listening to, can be seen as an empowering process, increasing self-efficacy (17) and thereby motivation.

Some respondents stated that they did not regard the prescribed exercises as training, but as a pleasant activity in which they were relaxed, thereby increasing interest/motivation.

In general, the respondents preferred non-pharmacological to pharmacological treatments, such as botulinum toxin and oral baclofen. Injections of botulinum toxin were described as having negative connotations and concerns about being harmful to the body. The respondents regarded the AT as an option that was preferable to botulinum toxin, for example. It can be assumed that the cost of healthcare does not differ substantially between these different treatment modalities, but this has to be elaborated through healtheconomic studies.

\section{Methodological considerations}

The decision to conduct a qualitative study is justified by the opportunity to elicit the respondents' experiences through individual interviews. The respondents had a need and an interest in talking about their experiences, which is a strength. Some interviews were wordy, while others were fairly brief, because of some respondents' difficulty expressing themselves due to their health condition. The quality of the interviews was improved, as the interviewer had a good knowledge of the subject, the interviews were structured and the respondents were aware of the purpose of the interview (18). 
The respondents' experiences relate to their entire participation in the study, i.e. not only the RCT part, but also the free phase (the final 34 weeks). We are not able to determine which part of the study was referred to in specific comments, and for this study this aspect is not relevant. There are both positive and negative connotations to participating in a study. One limitation of this study could be that 6-12 months elapsed between the previous study being completed and the interviews in this study being conducted.

Validity is strengthened by the study's variations in the respondents' age, sex and experience, but also in the sample size, 15 respondents from all 27 participants in the previous study.

\section{Summary}

The qualitative approach of this study elicited complementary information that was not evident from the previous study. In this study, using the Mollii Suit ${ }^{\circledR}$ in combination with training was reported to affect spasticity and thereby also mobility and pain (the results of the previous study did not report statistically significant effects at group level). Interest in testing the treatment came, at least in part, from the hope that the treatment might reduce spasticity without the side-effects experienced from pharmacological treatments. The reports from this study underline the general concern about choosing the right treatment for each individual. The respondents' hope of becoming more independent was not fulfilled for some of the respondents, as the AT was too difficult to put on, and thereby had the unintended effect of increasing dependence on others.

As a result, the respondents' overarching verdict, as expressed in their interest in continuing using the training concept, falls within the 4 main dimensions of outcome from using the AT, motivation to use the AT, usability of the AT and support in using the AT. These 4 dimensions are also recognized as essential for successful interventions from a clinical perspective.

This study also provided information about the importance of good communication with, and rapid response from, the AT provider. As this may affect compliance and adoption, it should be observed in the planning of AT studies.

\section{ACKNOWLEDGEMENTS}

This work was made possible by initial support from Sparbanksstiftelsen sjuhärad (grant no. 20152764). The authors gratefully acknowledge the respondents for their kind participation in the study.

The authors have no conflicts of interest to declare.

\section{REFERENCES}

1. Lundstrom E, Terent A, Borg J. Prevalence of disabling spasticity 1 year after first-ever stroke. Eur J Neurol 2008; 15: 533-539.

2. Shevell MI, Dagenais L, Hall N, Repacq C. The relationship of cerebral palsy subtype and functional motor impairment: a population-based study. Dev Med Child Neurol 2009; 51: 872-877.

3. Palmcrantz S, Pennati GV, Bergling H, Borg J. Feasibility and potential effects of using the electro-dress Mollii on spasticity and functioning in chronic stroke. J NeuroEngineering Rehabil 2020; 17: 109.

4. Flodström C, Viklund Axelsson S-A, Nordström B. A pilot study of the impact of the electro-suit Mollii ${ }^{R}$ on body functions, activity, and participation in children with cerebral palsy, Assist Technol 2021.

5. Hedin H, Wong $C$, Sjödén A. The effects of using an electrodress (Mollii ${ }^{\circledR}$ ) to reduce spasticity and enhance functioning in children with cerebral palsy: a pilot study. Eur J Physiother 2020.

6. Ertzgaard P, Alwin J, Sörbo A, Lindgren M, Sandsjö L. Evaluation of a self-administered transcutaneous electrical stimulation concept for the treatment of spasticity: a randomized placebo-controlled trial. Eur J Phys Rehabil Med 2018; 54: 507-517.

7. Kvale S, Brinkmann S. Interviews learning the craft of qualitative research interviewing. 3rd edn. London: Sage; 2015.

8. Dahlberg K, Dahlberg H, Nyström M. Reflective lifeworld research. Lund: Studentlitteratur; 2008.

9. Graneheim UH, Lundman B. Qualitative content analysis in nursing research: concepts, procedures and measures to achieve trustworthiness. Nurse Educ Today 2004; 24 : 105-112.

10. Doan VQ, Brascher A, Gillard JP, Varon SF, Vandenburgh AM, Turkel CC, et al. Relationship between disability and health-related quality of life and caregiver burden in patients with upper limb poststroke spasticity. Am Acad Phys Med Rehabil 2012; 481: 4-10.

11. Pradines M, Ghedira M, Portero R, Masson I, Marciniak C, Hicklin D, et al. Ultrasound structural changes in triceps surae after a 1-year daily self-stretch program: a prospective randomized controlled trial in chronic hemiparesis. Neurorehabil Neural Repair 2019; 33: 245-259.

12. Sandström K, Samuelsson K, Öberg B. Prerequisites for carrying out physiotherapy and physical activity - experiences from adults with cerebral palsy. Disabil Rehabil 2009; 31: 161-169.

13. Jahnsen R, Villien L, Egeland T, Stanghelle JK, Holm I. Locomotion skills in adults with cerebral palsy. Clin Rehabil 2004; 18: 309-316.

14. Montané E, Vallano A, Laporte J. R. Oral antispastic drugs in nonprogressive neurologic diseases. A systematic review. Neurology 2004; 63: 1357-1363.

15. Paasche Orlow $M$, Wolf $M$. The causal pathways linking health literacy to health outcomes. Am J Health Behav 2007; 31: 19-26.

16. BH Marcus, VC Selby, RS Niaura, JS Rossi. Self-efficacy and stages of motion behavior change. Research Quarterly for Exercise and Sport 2013; 60-66.

17. van Diemen T, Craig A, van Nes IJW, SELF-SCI Group. Enhancing our conceptual understanding of state and trait self-efficacy by correlational analysis of four self-efficacy scales in people with spinal cord injury. BMC Psychol 2020; 8: 108 .

18. Kvale S, Brinkmann S. Den kvalitativa forskningsintervjun. [The qualitative research interview]. Lund: Studentlitteratur; 2014 (in Swedish). 